\title{
PENGAWASAN DAN DISIPLIN TERHADAP KINERJA PEGAWAI PADA BADAN PERENCANAAN PEMBANGUNAN DAERAH
}

\author{
Astuti Yulia Fitri \\ astiyuliafitri@gmail.com \\ Sadikun Citra Rusmana \\ Universitas Pasundan \\ J1. Tamansari No. 6-8, Bandung 40116
}

diterima: 20/12/2019; direvisi: 26/1/2020; disetujui: 27/2/2020

\begin{abstract}
Supervision as one of the management functions in achieving goals, plays a very important role by monitoring the possibility of preventable deviations, then discipline is a tool used to communicate with employees so that they are willing to change behavior and as an effort to increase awareness and willingness to obey all company regulations and prevail social norms. The purpose of this study is to determine the responses of respondents and the influence of supervision, work discipline on employee performance at BAPPEDA Kota Bandung, simultaneously or partially. This research method is quantitative with multiple linear regression analysis techniques. The results showed consumer responses to supervision with a score of 3.73, discipline with a score of 3.76, and performance with a score of 3.77. There is as well as a positive and significant effect partially and simultaneously from supervision, discipline of employee performance at BAPPEDA Kota Bandung.
\end{abstract}

Keywords: supervision; discipline; employee performance; BAPPEDA; Bandung City; multiple linier regression

\begin{abstract}
Abstrak
Pengawasan sebagai salah satu fungsi manajemen dalam pencapaian tujuan, memegang peranan yang sangat penting dengan adanya pengawasan kemungkinan terjadinya penyimpangan dapat dicegah,selanjutnya disiplin merupakan suatu alat yang digunakan untuk berkomunikasi dengan karyawan agar mereka bersedia untuk mengubah suatu perilaku serta sebagai suatu upaya untuk meningkatkan kesadaran dan kesediaan dalam mentaati semua peraturan perusahaan dan normanorma sosial yang berlaku.Tujuan penelitian ini untuk mengetahui tanggapan responden dan pengaruh pengawasan, disiplin kerja terhadap .kinerja pegawai di BAPPEDA Kota Bandung, secara simultan maupun secara parsial. Metode penelitian ini kuantitatif dengan teknik analisis regresi linear berganda.Hasil penelitian menunjukkan tanggapan konsumen terhadap pengawasan dengan skor 3,73, disiplin dengan skor 3,76, dan kinerja dengan skor 3,77. Serta adanya pengaruh positif dan signifikan secara parsial dan simultan dari pengawasan, disiplin terhadap kinerja pegawai di BAPPEDA Kota Bandung.
\end{abstract}

Kata Kunci: pengawasan; displin; kinerja pegawai; BAPPEDA; Kota Bandung; regresi linier berganda 


\section{PENDAHULUAN}

Setiap instansi pemerintahan dituntut untuk dapat mengoptimalkan sumber daya manusia dan bagaimana sumber daya manusia dikelola. Pengelolaan sumber daya manusia tidak lepas dari faktor pegawai yang diharapkan dapat berprestasi sebaik mungkin demi mencapai tujuan instansi pemerintahan. Pegawai merupakan asset utama instansi dan mempunyai peran yang penting di dalam instansi yaitu sebagai pemikir, perencana dan pengendali aktivitas instansi. Pengawasan sebagai salah satu fungsi manajemen dalam pencapaian tujuan, memegang peranan yang sangat penting karena dengan adanya pengawasan kemungkinan terjadinya penyimpangan dapat dicegah, sehingga usaha untuk mengadakan perbaikan atau koreksi dapat segera dilakukan.

Robert J. Mockler dalam Handoko (2015) mengemukakan bahwa pengawasan adalah suatu usaha sistematik untuk menetapkan standar pelaksanaan dengan tujuan-tujuan perencanaan, merancang sistem informasi umpan balik, membandingkan kegiatan nyata dengan standar yang telah ditetapkan sebelumnya, menentukan dan mengukur penyimpangan-penyimpangan, serta mengambil tindakan koreksi yang diperlukan untuk menjamin bahwa sumber daya perusahaan digunakan dengan cara paling efektif dan efisien dalam pencapaian tujuan-tujuan perusahaan. Sedangkan Earl P. Strong dalam Hasibuan (2014) berpendapat bahwa controlling is the process of regulating the various factors in an enterprise according to the requirement of its plans.Pendapat tersebut menyatakan bahwa pengawasan adalah proses pengaturan berbagai faktor dalam suatu perusahaan, agar pelaksanaan sesuai dengan ketetapan-ketetapan dalam rencana.

Rivai (2011) berpendapat bahwa disiplin kerja adalah suatu alat yang digunakan para manajer untuk berkomunikasi dengan karyawan agar mereka bersedia untuk mengubah suatu perilaku serta sebagai suatu upaya untuk meningkatkan kesadaran dan kesediaan seseorang dalam mentaati semua peraturan perusahaan dan norma-norma sosial yang berlaku.

Tabel 1 merupakan perbandingan capaian indikator kinerja dengan Satuan Kerja Perangkat Daerah (SKPD) sejenis, tampak Badan Perencanaan Pembangunan Daerah (BAPPEDA) Kota Bandung berada pada urutan 27, dengan demikian harus dapat meningkatkan nilai evaluasi Akuntabilitas Kinerja Instansi Pemerintah agar lebih kompetitif terhadap SKPD lain.Apalagi BAPPEDA merupakan lembaga teknis dilingkungan Pemerintahan Daerah Tingkat II Kota Bandung. Fungsi dan peran instansi sebagai lembaga teknis daerah yang bertangung jawab terhadap perencanaan pembangunan sebagaimana diamanatkan dalam pasal 14 ayat (1), Undang-undang Nomor 32 Tahun 2004 tentang Pemerintah Daerah, bahwa salah satu urusan wajib yang menjadi kewenangan pemerintah daerah adalah urusan perencanaan dan pengendalian pembangunan. Serta sebagai instansi teknis pemerintah dituntut untuk memberikan kinerja yang optimal dalam pelaksanaan perencanaan pembangunan daerah karena tugas dan fungsi dari instansi ini adalah melaksanakan berbagai urusan pemerintah lingkup manajemen kepegawaian, sehingga kinerja pegawai instansi ini secara umum menjadi sorotan dan panutan untuk badan-badan pemerintah Kota Bandung lainnya.

Berdasarkan Peraturan Pemerintah No.46 Tahun 2011 tentang Penilaian Kinerja Pegawai Negeri Sipil. Gambar 1 menunjukkan pencapaian kinerja pegawai dari tahun 2013 sampai dengan 2016. Berdasarkan fenomena yang terjadi maka dilakukan penelitian yang berkaitan dengan pengawasan, disiplin serta kinerja pada BAPPEDA Kota Bandung.

Pengawasan kerja mempengaruhi kinerja pegawai, pernyataan ini diperkuat dengan penelitian Yamoah (2014), menunjukkan bahwa pemantauan yang efektif dapat meningkatkan kinerja para karyawan. Hal ini juga didukung dengan pendapat dari Armstrong dan Baron (2005) bahwa meningkatnya kinerja karyawan apabila koreksi dilakukan tepat waktu. Disiplin kerja dapat diartikan mematuhi semua peraturan dan normanorma yang berlaku di suatu perusahaan atau instansi. agar pegawai menepati segala peraturan dan kebijakan instansi yang berlaku, dengan sukarela mematuhi serta menaati tata tertib tanpa ada paksaan. Pencapaian tujuan memerlukan pegawai yang penuh kesadaran, kesetiaan, ketaatan dan rasa tanggung jawab atas segala pekerjaan.

Disiplin kerja dapat mempengaruhi kinerja pegawai, pernyataan ini diperkuat penelitian Tumilaar (2015). Hal ini juga didukung dengan pendapat dari Hasibuan (2014), semakin baik disiplin karyawan, semakin tinggi prestasi kerja yang dapat dicapainya. Hipotesis penelitian ini adalah pengawasan dan disiplin berpengaruh positif secara simultan dan parsial terhadap kinerja pegawai.

\section{METODE}

Metode penelitian ini menggunakan pendekatan kuantitatif, dengan menggunakan teknik analisis regresi liniear berganda. Populasi adalah pegawai BAPPEDA Kota Bandung, dengan jumlah 91 orang pegawai. Teknik pengambilan sampel yang digunakan adalah probability sampling, dengan jenis kriteria sampel adalah sampling jenuh. Teknik pengumpulan data dilakukan dengan menyebarkan kuesioner kepada responden dan studi pustaka.Skala pengukuran yang digunakan adalah skala likert. Operasionalisasi variabel ditunjukkan pada Tabel 3.

\section{HASIL}

Karateristik responden didominasi oleh jenis kelamin laki-laki sebesar 59,3\%, usia 37- 45 tahun sebesar 38,5\%, tingkat pendidikan S1 sebesar 54,9\%, masa kerja 10-15 tahun sebesar 43,9\%. Berdasarkan hasil perhitungan dengan Microsoft Excel didapatkan total skor pengawasan sebesar 3,73, disiplin sebesar 3,76, kinerja sebesar 3,77 berada pada kategori baik. 
Uji validitas pada pernyataan kuesioner menunjukkan hasil validitas dan reliabel.

Berdasarkan hasil analisis regresi liniear berganda, didapat nilai konstanta dan koefisien regresi sebagai berikut (Tabel 4):

$$
\mathrm{Y}=0,284+0,215 \mathrm{X}_{1}+0,702 \mathrm{X}_{2}
$$

Berdasarkan hasil pengujian koefisien determinasi pada Tabel 5 didapat nilai $\mathrm{R}$ Square 0,649 yang menunjukkan bahwa pengawasan dan disiplin memberikan pengaruh $64,9 \%$ terhadap kinerja pegawai.

\section{PEMBAHASAN}

Pengawasan memiliki pengaruh yang signifikan terhadap kinerja pegawai pada BAPPEDAKota Bandung. Koefisien regresi variabel pengawasan memilki nilai positif. Hal ini menunjukkan bahwa variabel pengawasan memiliki hubungan searah dengan kinerja pegawai. Apabila pengawasan instansi tinggi, maka akan meningkatkan kinerja pegawai pada BAPPEDA Kota Bandung. Disiplin memiliki pengaruh signifikan terhadap kinerja pegawai pada BAPPEDA Kota Bandung. Koefisien regresi variabel disiplin memilki nilai positif. Hal ini menunjukkan bahwa variabel disiplin memiliki hubungan searah dengan kinerja pegawai. Apabila disiplin instansi tinggi, maka akan meningkatkan kinerja pegawai pada BAPPEDA Kota Bandung. Pengawasan dan disiplin memberikan kontribusi pengaruh terhadap kinerja pegawai sebesar $64,9 \%$ pada BAPPEDA Kota Bandung.

Hasil penelitian ini memperkuat penelitian Marpaung dan Agustin (2013), Setiawan (2013), Nurjaman (2012), dan Tumilaar (2015). Sementara penelitian lain menyebutkan bahwa pengawasan dan disiplin berpengaruh positif dan signifikan antara penilaian kinerja dan kepuasan kerja.Patmarina dan Wasilawati (2014), hanya saja pada penelitian ini menambahkan variabel kepuasan kerja.

\section{KESIMPULAN}

Berdasarkan pada hasil penelitian yang telah dilakukan, didapatkan 4 (empat) kesimpulan, sebagai berikut: (1) tanggapan responden terhadap pengawasan dan kinerja berada pada kategori baik, pada garis kontinum tanggapan responden tersebut; (2) pengawasan dan disiplin memiliki pengaruh positif dan signifikan terhadap kinerja pegawai; (3) pengawasan memiliki pengaruh positif dan signifikan terhadap kinerja pegawai; (4) disiplin memiliki pengaruh positif dan signifikan terhadap kinerja pegawai.

\section{DAFTAR PUSTAKA}

Armstrong, M. and Baron, A. 2005. Managing performance: performance management in action. CIPD publishing.

Handoko. 2015. Manajemen Personalia dan Sumber Daya Manusia. Edisi 2, BPFE, Yogyakarta.

Hasibuan. 2014. Manajemen. Edisi revisi, cetakan ke 10. PT. Bumi Aksara, Jakarta.

Marpaung, R. and Agustin, T.D. 2013. Pengaruh Pengawasan Dan Disiplin Kerja Terhadap Kinerja Pegawai Kejaksaan Tinggi Riau. Jurnal Sosial Ekonomi Pembangunan, 3(8), pp.141-164.

Nurjaman. 2012. Pengaruh Pengawasan terhadap Kinerja Pegawai melalui Motivasi Kerja Studi kasus di Inspektorat Kabupaten Indramayu. Jurnal Unwir, http://ejournal.unwir.ac.id

Patmarina, H. and Wasilawati, W. 2014. Pengaruh Pengawasan dan Disiplin Kerja Terhadap Kinerja dengan Mediasi Prestasi Kerja Koordinator Statistik Kecamatan (Study Kasus pada Badan Pusat Statistik Kabupaten Lampung Tengah). Jurnal Manajemen dan Bisnis, 5(1), pp.63-83.

Rivai, V. 2011. Manajemen Sumber Daya Manusia Untuk Perusahaan Dari Teori ke Praktek, Ghalia Industri, Bogor.

Setiawan, A. 2013. Pengaruh disiplin kerja dan motivasi terhadap kinerjakaryawan pada rumah sakit umum daerah kanjuruhan malang. Jurnal Ilmu Manajemen (JIM), 1(4).

Tumilaar, B. R. 2015. The effect of discipline, leadership, and motivation on employee performance at bpjs ketenagakerjaan Sulut. Jurnal EMBA: Jurnal Riset Ekonomi, Manajemen, Bisnis Dan Akuntansi, 3(2).

Yamoah, E. E. 2014. Monitoring Employee Performance at the Workplace. Developing Country Studies. Albany. 
Tabel 1. Nilai Evaluasi AKIP SKPD di Lingkungan Pemerintah Kota Bandung Tahun 2017

\begin{tabular}{clc}
\hline No & \multicolumn{1}{c}{ SKPD } & Nilai Evaluasi AKIP \\
\hline 1 & Sekretariat Daerah & 78,6 \\
2 & Dinas Bina Marga Dan Pengairan & 78,21 \\
3 & Dinas Pertanian Dan Ketahanan Pangan & 77,15 \\
4 & Dinas Kesehatan & 75,86 \\
5 & Inspektorat & 75,14 \\
6 & DPKAD & 74,7 \\
7 & BPPT & 74,22 \\
8 & BPPKB & 73,84 \\
9 & RSUD Kota Bandung & 73.79 \\
10 & RSKIA & 73,39 \\
11 & BKD & 72,47 \\
12 & RSKGM & 72,19 \\
13 & Dinas Koperasi Usaha Kecil Menengah & 70,83 \\
14 & Dinas Pendidikan & 70,11 \\
15 & Dinas Perhubungan & 69,87 \\
16 & Sekretariat DPRD & 69,81 \\
17 & BPLH & 69,04 \\
\hline
\end{tabular}

\begin{tabular}{lll}
\hline 18 & Dinas Tenaga Kerja & 68,92 \\
19 & Dinas Kebudayaan Dan Pariwisata & 68,82 \\
20 & Dinas Kependudukan Dan Catatan Sipil & 68,6 \\
21 & Dinas Tata Ruang Dan Cipta Karya & 68,42 \\
22 & Kantor Arpusda & 67,78 \\
23 & Dinas Pelayanan Pajak & 67,43 \\
24 & Diskominfo & 67 \\
25 & Kantor Satpol PP & 66,85 \\
26 & Dinas Sosial & 66,83 \\
27 & BAPPEDA & 66,57 \\
\hline
\end{tabular}

Tabel 2. Standar Nilai Kinerja Pegawai

\begin{tabular}{ccc}
\hline No & Nilai $(\%)$ & Keterangan \\
\hline 1 & $91-$ ke atas & Sangat Baik \\
2 & $76-90$ & Baik \\
3 & $61-75$ & Cukup \\
4 & $51-60$ & Kurang \\
5 & 50 ke bawah & Buruk \\
\hline \multicolumn{2}{l}{ Sumber : Peraturan Pemerintah No. 46 Tahun 2011 }
\end{tabular}

Tabel 3. Operasionalisasi Variabel

\begin{tabular}{llll}
\hline Variabel/ Konsep Variabel & \multicolumn{1}{c}{ Dimensi } & \multicolumn{1}{c}{ Indikator } & \multicolumn{1}{c}{ Ukuran } \\
\hline Pengawasan $\left(\mathrm{X}_{1}\right)$ & 1. Prosedur & Pemberian prosedur kepada pegawai & Tingkat pengawasan sesuai prosedur yang ada \\
Penemuan dan penerapan & 2. Standar & Penyampaian standar instansi & Tingkat penyampaian prosedur yang dibuat Instansi \\
cara dan peralatan untuk & 3. Ketelitian & Pemeriksaan kebenaran laporan & Tingkat ketelitian dalam pemeriksaan laporan \\
menjamin bahwa rencana & 4. Pengukuran & Pemberian penilaian terhadap & Tingkat pengawasan terhadap hasil kerja \\
yang telah direncanakan & Pekerjaan & pelaksanaan pekerjaan & \\
$\begin{array}{l}\text { sesuai dengan yang telah } \\
\text { diciptakan }\end{array}$ & 5. Perbaikan & Pembetulan atas penyimpangan & Tingkat pelaksanaan pengawasan kerja yang sesuai \\
& & & dengan standar
\end{tabular}

$\begin{array}{lll}\text { Disiplin Kerja }\left(\mathrm{X}_{2}\right) & \text { 1. Frekuensi } & \text { a. Absensi (ketidakhadiran) } \\ \text { Disiplin kerja adalah sikap kehadiran } & \text { b. Tepat waktu } \\ \text { menghormati, menghargai, 2. Tingkat } & \text { a. Ketelitian } \\ \text { patuh dan taat terhadap } & \text { Kewaspadaan } & \text { b. Perhitungan (pertimbangan) } \\ \text { peraturan yang berlaku baik } & \text { 3. Ketaatan } & \text { a. Menaati aturan dan pedoman kerja } \\ \text { yang tertulis maupun yang } & \text { Pada Standar } & \text { b. Tanggung Jawab } \\ \text { tidak tertulis serta sanggup } & \text { Kerja } & \\ \text { menjalankannya dan tidak } & \text { 4. Ketaatan } & \text { Menaati peraturan kerja } \\ \text { mengelak meneriman sanksi- Pada Peraturan } & \\ \begin{array}{l}\text { sanksi apabila ia melanggar } \\ \text { tugas dan wewenang yang }\end{array} & & \text { b. Etika Kerja } \\ \text { diberikan kepadanya. } & \text { a. Kaling menghormati }\end{array}$

Kinerja Pegawai (Y) 1. Kualitas

Kinerja pegawai adalah Kerja

hasil kerja secara kualitas

dan kuantitas yang dicapai 2. Kuantitas

oleh seorang pegawai dalam Kerja

melaksanakan tugasnya 3 . Tanggung

sesuai dengan tanggung Jawab

jawab yang diberikan.
Tingkat ketidakhadiran kerja

Tingkat Ketepatan waktu dalam masuk kerja

Tingkat Ketelitian dalam menjalankan pekerjaan

Tingkat mengurangi risiko menjalankan pekerjaan

Tingkat ketaatan pada standar kerja

Tingkat Hasil kerja pada standar kerja

Tingkat ketaatan pada peraturan kerja

Tingkat keharmonisasian antar pegawai

Sikap menghargai antar pegawai

Tingkat kerapihan dalam mengerjakan pekerjaan Tingkat ketepatan dalam mengerjakan pekerjaan Tingkat ketelitian dalam megerjakan pekerjaan Tingkat kecepatan dalam mengerjakan pekerjaan Hasil kerja yang memuaskan pimpinan Tingkat tanggung jawab atas hasil pekerjaan Tingkat Penggunaan sarana dan prasarana Hubungan kerjasama yang baik dengan pimpinan Tingkat Kekompakan Tingkat kemandirian melaksanakan pekerjaan 
Tabel 4. Hasil Koefisien regresi X terhadap Y

Coefficients $^{\mathrm{a}}$

\begin{tabular}{|c|c|c|c|c|c|c|c|c|c|}
\hline \multirow[b]{2}{*}{ Model } & & \multicolumn{2}{|c|}{$\begin{array}{c}\text { Unstandardized } \\
\text { Coefficients }\end{array}$} & \multirow{2}{*}{$\begin{array}{c}\begin{array}{c}\text { Standardized } \\
\text { Coefficients }\end{array} \\
\text { Beta } \\
\end{array}$} & \multirow[b]{2}{*}{$\mathrm{T}$} & \multirow[b]{2}{*}{ Sig. } & \multicolumn{3}{|c|}{ Correlations } \\
\hline & & $\mathrm{B}$ & Std. Error & & & & Zero- order & Partial & Part \\
\hline \multirow[t]{3}{*}{1} & (Constant) & .284 & .225 & & 1.261 & .211 & & & \\
\hline & Pengawasan $\left(\mathrm{X}_{1}\right)$ & .215 & .064 & .243 & 3.364 & .001 & .561 & .338 & .212 \\
\hline & Disiplin $\left(\mathrm{X}_{2}\right)$ & .702 & .077 & .660 & 9.152 & .000 & .777 & .698 & .578 \\
\hline
\end{tabular}

a. Dependent Variable: Kinerja Pegawai (Y)

Tabel 5. Korelasi Ganda X- Y

Model Summary ${ }^{\mathrm{b}}$

\begin{tabular}{ccccc}
\hline Model & $\mathrm{R}$ & R Square & Adjusted R Square & Std. Error of the Estimate \\
\hline 1 & $.806^{\mathrm{a}}$ & .649 & .641 & .35131 \\
\hline
\end{tabular}

a. Predictors: (Constant), Disiplin Kerja $\left(\mathrm{X}_{2}\right)$, Pengawasan Kerja $\left(\mathrm{X}_{1}\right)$

b. Dependent Variable: Kinerja Pegawai (Y)

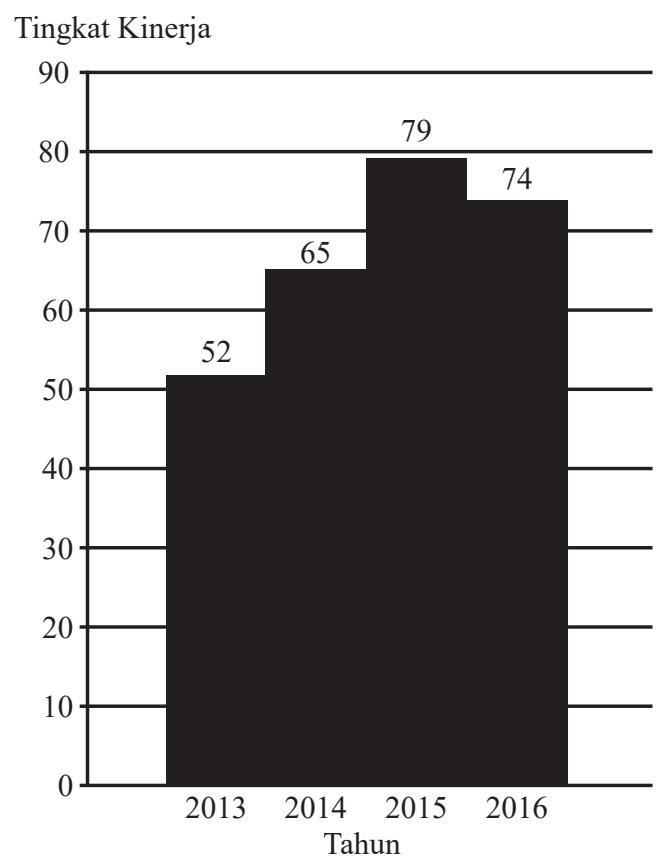

Gambar 1. Hasil Penilaian SKP Pada BAPPEDA Kota Bandung Periode 2013-2016 